\title{
How Are Students Immersed by Providing Virtual Reality Technology? The Role of Psychological Distance in Online Flipped Class
}

\author{
Lyu Hongyu
}

\begin{abstract}
Online flipped Class can be optimized by introducing VR technology. By adding VR technology to the online flipped class, the performance of class and students' learning efficiency could be affected. Therefore, we investigate the effects of incorporating VR technology in online flipped classes. In this study, we contend that the effects of VR on online flipped class can be theoretically modelled as users' attitudes about VR features that influence their psychological distance, which in turn shapes their attitudes and behaviors towards using the learning platform. Finally, we postulate a lab experiment to measure whether the VR technology in flipped class can increase students' engagement.
\end{abstract}

Index Terms-Flipped class, virtual reality, learning efficiency.

\section{INTRODUCTION}

At present, the development of technology has widely applied virtual reality (VR) technology in the field of games and e-commerce. For example, China's virtual reality market is forecast to expand 54.45 billion yuan (US\$7.9billion) by $2021{ }^{1}$ However, even the populations and economies of VR are rapidly growing in many fields, the most education courses are not explicitly designed to apply VR. Some universities started to use VR in virtual surgery medicine and hazard experiment courses. The virtual reality research group of East China University of Science and Technology in Shanghai uses virtual reality technology to simulate the fire scene, including the cause of fire and the response of the injured and the reaction of the injured. The controller allows delegates to explore and interact with a computer simulation environment, such as opening a door or picking up objects from the ground. In this way, firefighters can be trained to conduct life-saving exercises in virtual scenes. The natural human-computer interaction of virtual reality technology greatly improve the degree of immersion. ${ }^{2}$

Flip classroom, as a means of increasing the interaction between teachers and students, is popular nowadays. In a flip classroom, students collaborate in group discussions instead of listening lectures, carry out courses preparation at home while engaging in discovering new concepts in the classroom.

Manuscript received October 1, 2019; revised November 29, 2019.

Lyu Hongyu is with Hanshan Normal University, China (e-mail: lhy149096@gmail.com).

${ }^{1}$ https://amp.scmp.com/tech/gear/article/3015591/chinas-virtual-realitymarket-set-expand-driven-increased-policy-support

${ }^{2}$ http://www.chinadaily.com.cn/a/201907/17/WS5d2e9171a3105895c2e 7de92.html
For instance, Gilboy [1] used a flip classroom in a nutrition course. While organizing the curriculum, they divided the learning content into three stages: before class, in class, and after class. Before-class, the teacher uploads the video containing basic knowledge and concepts to the learning platform. Students need to preview the learning contents, search for related information on the Internet, and write down the questions they encounter. In class, the teacher and students have face-to-face interaction and discussion of these questions. The students are given individualized guidance to clarify misunderstood concepts. Besides, they are divided into groups and conclude the learning contents to reinforce their memory by exchanging opinions. After class, students are given a pencil-and-paper test to assess their learning status. The results show that with this teaching approach not only students' learning results are increased, but also both the students' and the teacher's satisfaction with the course tends to be high [1].

However, it is hard to introduce this amazing approach to e-learning context. One major problem is the enthusiasm of teacher-student interaction discussion is relatively low in online flip classroom. Therefore, reducing the communication barrier between teachers and students is important to apply flip classroom to online education context. The application of VR technology with unique characteristics can improve interaction online. For example, when students' psychological space distance is large, students will be unwilling to communicate and think that they are far away from each other. What' s more, when students have a large psychological social distance, students are unwilling to take the initiative to discuss problems with their classmates or ask questions to teachers.

Therefore, this study incorporates VR technology to online flipped class to increase the interactions among students and teachers online. Our research question is whether incorporating VR technology increase students' engagement in online flipped classes? By adding VR technology to the e-learning context, the educational quality and students' learning efficiency of online flip classroom might be improved. At the same time, it can also avoid certain negative effects of VR. Previous scholars have studied it has some advantages, but it still has disadvantages. Whether the flipping classes can be applied to online education are seldom discussed. In the field of education, the application of VR technology in experimental teaching has been investigated. But so far, there is no research that combines online flip classes with VR technology. This paper will combine the two and promote this field. 
So that we investigate how VR can help students improve their learning efficiency in online flipped class. Our motivation is to explore the effects of VR technology in online flip classroom through psychological distance perspective. In the second part of the following section, we will refer to the literature review. The third part is the theoretical development and hypothesis. The fourth part is the experimental design. And finally is the general discussion and further study plan.

\section{LITERATURE REVIEW}

\section{A. Flipped Class in e-Learning}

Previous research has indicated that flip classroom is an instructional strategy and a blended learning that reverses the traditional learning environment by delivering instructional content, often online, outside of the classroom. ${ }^{3}$ It moves activities, including those that may have traditionally been considered homework, into the classroom. But in this study, the discussion of flip classroom will be adapted to an online context. This means that in our context, teachers and students do not have the opportunity to meet offline.

For online education, the most obvious benefit is that using computers or other forms of technology can give students practice on core content and skills while the teacher can work with others, conduct assessments, or perform other tasks [2]. Modern educational technology can improve access to education [3] and improved interactions between students and instructors [4], and learning material can be used for long distance learning and are accessible to a wider audience. Course materials are easy to access [3]. Furthermore, the development of educational apps generally has a positive effect on learning. Previous studies reveal that the use of apps on mobile devices reduces the achievement gap between struggling and average students [5]. However, technology itself, does not necessarily result in fundamental improvements to improve educational practice [6]. Social relationships are important but high-tech environments may compromise the balance of trust, care and respect between teacher and student [7]. Certain curriculum and teaching methods are also superior, and this could eventually wash over (or possibly washing out) local educational institutions, cultural norms and educational traditions [8]. What's more, it may also increase potential for cheating. 4 .

As for offline context, teaching and learning by face-to-face is essential for some people to learn effectively. Getting instant answers, and developing a support network with fellow students, teachers and the training provider as a whole. At the same time, students can stay motivated because, in order to complete the course, they have to attend a certain number of sessions ..$^{5}$ For the drawbacks, firstly, it can bring back uncomfortable memories of times spent in school, as well as it can make participants feel cloistered and closed. ${ }^{4}$ Secondly, the cost of school equipment and the transportation of students may relatively high. Thirdly, for students who

\footnotetext{
${ }^{3}$ https://en.wikipedia.org/wiki/Flipped_classroom

4"Baby Einsteins: Not So Smart After All," TIME.com. 6 August 2007

${ }^{5} \mathrm{https}$ ://www.ncchomelearning.co.uk/blog/distance-learning-vs-face-to-f ace-benefits-and-drawbacks/
}

have difficulties in their lives, or work and family commitments, missing a few sessions can lead to the sense of 'no point carrying on, I've missed too much'. Because they have no way to study online. ${ }^{4}$

\section{B. VR, MR and AR Technology}

Virtual reality (VR) is the use of computer graphics systems in combination with various display and interface devices to provide the effect of immersion in the interactive 3D computer-generated environment [9]. We call such an environment a virtual environment (VE). Research and development into VR and VE applications can be found in many places all over the world. Mixed reality (MR) refers to the incorporation of virtual computer graphics objects into a real three-dimensional scene, or alternatively the inclusion of real-world elements into a virtual environment [9]. The former case is generally referred to as augmented reality, and the latter as augmented virtually [9]. Augmented reality (AR) is an interactive experience of a real-world environment where the objects that reside in the real-world are "augmented" by computer-generated perceptual information, sometimes across multiple sensory modalities, including visual, auditory, haptic, somatosensory, and olfactory. ${ }^{6}$ The overlaid sensory information can be constructive (i.e. additive to the natural environment) or destructive (i.e. masking of the natural environment) and is seamlessly interwoven with the physical world such that it is perceived as an immersive aspect of the real environment [10].

Suppose the teachers and classmates are put into the same space by holographic projection technology in the on-line flipping class. For teachers, the effect of teaching and the attraction of the classroom will be enhanced. For students, they can focus more on learning and thus their learning efficiency will be improved. The second aspect is students' psychological distance with teacher. Moore (1973) regarded distance education as a transaction and asserted that the physical separation in distance education leads to a psychological space of potential misunderstandings and a communication gap (i.e., transactional distance) between the instructor and the learner [11]. Therefore we propose that VE technology will shorten the psychological distance between teachers and students. The next aspect is students' attention is different in virtual and non-virtual environments. The last aspect is application of VE in Network education platform. Increasingly scientists are using virtual technology for visualization and in particular as a teaching aid [12]. But virtual technology is also facing a lot of obstacles. For example, the supply and price of equipment, and students' physical adaptation (long periods of time may cause vertigo).

In summary, prior research has shown that it is important to apply VR technology to online education, and many previous studies have been investigated this phenomenon. The main problem lies in three aspects, the first is the maturity and price of technology, the second is whether teachers can adapt and apply the technology well, and the third is the most critical point, how technology improve students' learning efficiency. Students' learning motivation is the main factor affecting the reduction and completion rate of

\footnotetext{
${ }^{6}$ https://en.wikipedia.org/wiki/Augmented_reality
} 
online courses, and the lack of motivation is also related to the high dropout rate [12].

\section{RESEARCH MODEL AND HYPOTHESIS DEVELOPMENT}

\section{A. Psychological Distance Theory}

In this situation, the psychological distance is the psychological distance among students and teaching objectives, which include teachers and learning contents. The psychological distance will influence the students' immersion and participation, so as to imagine whether it will have an impact on the learning efficiency.

Social distance refers to teacher-student interaction and observation, including emotional and behavioral aspects. For example, in flipping the classroom, the VR technology has the ability to let the teacher know the students' emotions and focus in time, the students can also observe the teacher's state of the class for interactive communication. Spatial distance refers to the psychological distance between two people in different spaces. This paper refers to the psychological distance between students and teachers and classmates in virtual classroom. VR technology allows everyone to be in the same space and close to the distance between the students and the teacher. While, hypothetical distance refers to the certainty or acceptance of learning content or results.

\section{B. VR Features}

VR has its unique features with different degree of immersion. Virtual reality environment is also the ability to visually depict and interact with spatial representations of abstract concept [13]. In this paper, immersion and participation are directly related to each other, thus affecting the interaction between students and platforms and teachers. According to the characteristics of VR, we propose three dimensions of immersion: mental immersion, spatial immersion and kinesthetic immersion. Immersion into virtual reality is a perception of being physically present in a non-physical world. The perception is created by surrounding the user of the VR system in images, sound or other stimuli that provide an engrossing total environment. ${ }^{7}$ For instance, the use of VR technology in online flipping classes can give a person the feeling of interacting in a real classroom, with feeling and touching the taught instrument.

In this scenario, students can choose between space scenarios (e.g., libraries, public lounges, classrooms, cafes, etc.). Different scenarios may have different effects on students and teachers. And kinesthetic immersion includes subjective feelings such as tactile, which mainly emphasizes a series of reactions produced by students when their bodies participate in classroom interaction.

\section{Hypothesis Development}

Combined with our previous research on the technical characteristics of VR and the definition of psychological distance, we think that there exists a certain logical relationship between them. We assume that the feature of VR can reduce psychological distance and thus increase student participation. Zhigeng Pan (2006) developed a teaching

${ }^{7}$ https://en.wikipedia.org/wiki/Immersion_(virtual_reality)\#Perception software for virtual reality technology, which they believe students can learn by working in groups to enhance their social skills in the process of learning using the software [9]. Therefore, we assume that:

H1 Mental immersion can reduce students' social distance.

Their research also collected learning feedback from involved students, and the teacher said virtual reality technology strengthens students' co-operation. Therefore, we assume that:

H2 Reduced social distance can enhance participation.

Virtual reality technology can make students and teachers in the same space to a large extent, and the spatial distance between them is reduced. Prior study illustrate that the greatest advantage of virtual reality technology is that it is economical, efficient, that people no longer have to go to the same place to meet, and that they are better able to immerse themselves in the educational environment and social learning [14]. Today, many businesses use VR or 3D surround technology to enhance the audience's spatial immersion. Therefore, we assume that:

H3 Spatial immersion can reduce the sense of space distance.

Sonja Kotz proposed that, in comfortable space distance, people will be more pleasant to get along with others [15]. In the case of a shorter space distance, students may remain motivated. So we put forward the assumption that:

H4 Reduced spatial distance can enhance participation.

Zhigeng Pan (2006) designed a virtual bowling game machine [9]. Players throw a real bowling ball, systematically analyze the trajectory parameters, and display the results on a large screen. Given the need for real-world equipment to use the virtual gaming system, and virtual scenes combined with real bowling can greatly increase augmented reality and thus reduce uncertainty. Similarly, kinesthetic perception is also a hot issue in the field of education. Kinesthetic learning is a learning style in which learning takes place by the students carrying out physical activities, rather than listening to a lecture or watching demonstrations. Ben-Zion (1999) defines exercise learning as a process of generating a new understanding through learners' participation in physical movement [16]. We propose the following assumptions:

H5 Kinesthetic immersion can reduce uncertainty about the results.

When a teacher asks a question in class, if the answer is uncertain, the students are less motivated to answer it. If it is a question of high certainty, the students will scramble to answer it. There is an interesting phenomenon on China's famous question-and-answer website, Zhihu app: the simpler the question, the more people answer it, and the fewer people who answer the more professional questions.

H6 Higher levels of information uncertainty can reduce the level of participation.

Previous literature found that students with low classroom participation were more likely to drop out of school and those with higher participation were more likely to complete their studies [17]. Therefore, we assume that:

H7 High participation can enhance learning efficiency.

From the above hypothesis, we propose the following proposed model: 


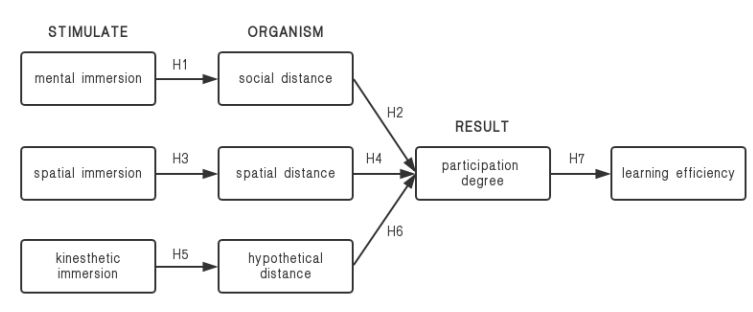

Fig. 1. Proposed model.

\section{EXPERIMENT DESIGN}

We're going to use experiments to verify the proposed model. The reason for using the experimental method is that the experimental results can be more scientific and rigorous than other survey methods.

Specify stimulation and rating: divided into 4 groups with VR and no VR devices (3 groups with VR device variables, 1 group without VR devices).

We will control the variables in the experiment, including other factors except VR, such as the time point of the experiment, the length of the experiment time, the temperature and humidity of the laboratory, and so on. In the selection and distribution of experimental subjects, we are going to select 20 males and 20 females from the same university to participate our pretest. The experiment will be divided into two large groups: the first group will use VR devices (which were divided into three groups to test three kinds of immersion), and the second group will not use VR devices. The experiment will let participants learn new knowledge in the online flipped class course. Participants will be asked to complete the 10 multiple choice questions after class test to see the psychological distance and their satisfaction towards the class.

Experimental design procedure is that, participants go to the laboratory in 4 batches to wait for the experiment and fill in the basic data.

1) The first large group carries out tests with VR devices.

The first group carries out mental immersion variable (Communication situation between people in 3D Environment) control. Participants will learn new knowledge in online courses and complete 10 multiple choice questions after class.

The second group controls spatial immersion variables (changing learning scenarios in equipment, such as library playground lounge, etc.). After learning new knowledge in the online course, participants will complete the 10 multiple choice questions test after class.

The third group controls kinesthetic immersion variables (such as virtual blackboard: the teacher writes on the virtual blackboard and automatically saves blackboard pictures after class). Participants will learn new knowledge in online courses and complete 10 multiple choice questions after class.

2) The second large group tested without VR devices

Participants use computers to learn online flipped classes course without using VR devices.

Manipulation Check: We will check whether the three groups of stimuli can reflect the differences of the three kinds of dimensions during the experiment.
Social distance and hypothetical distance measurement items are adapted from Peter R. Darke [18]. Spatial distance is adapted from Yoav Bar-Anan and Nira Liberman [19].

\section{DISCUSSION}

In this study, we find that VR technology has many characteristics in the online flip classroom, especially in mental immersion, spatial immersion and kinesthetic immersion, which affect social distance, spatial distance and hypothetical distance, respectively. From this series of interactions, we make the assumption that VR technology can improve students' participation in online flipped class. This study mainly investigates whether the use of VR technology in online flip classroom can improve students' learning efficiency. This study combines the concept of flipped classroom and the psychological distance theory in online education context, with incorporating the features of VR technology. It expands the applicable range of psychological distance theory. At the same time, this paper also puts forward the three characteristics of VR: mental immersion, spatial immersion and kinesthetic immersion. Among them, kinesthetic immersion is developed accounting to the unique characteristics of VR context. As for practical implication, the different functions of VR can meet the different needs of the students. When students need to improve their sense of distance, the platform can use VR's spatial immersion to help reduce spatial distance. For teacher and students, importing VR technology into the classroom can not only help solving existing problems, but also change the classroom into a highly interactive space to educate. Different teaching scenarios can use different functions. VR technology can not only benefit online platforms, but can also bring some business opportunities for related technical companies. These company can develop VR related tools for proving better usage experiences for both online platforms and students.

At present, we have designed the pretest part. There are still some problems about the practical application and implementation of VR in online flipped class to be discussed. As mentioned earlier, there are still many aspects of the e-learning system that need to be improved. Therefore, future research needs to be combined with experimental results and platform applications to verify our vision.

\section{CONFLICT OF INTEREST}

The authors declare no conflict of interest.

\section{AUTHOR CONTRIBUTIONS}

This study combines the concept of flipped classroom and the psychological distance theory in online education context, with incorporating the features of VR technology. It expands the applicable range of psychological distance theory. At the same time, this paper also puts forward the three characteristics of VR: mental immersion, spatial immersion and kinesthetic immersion. Among them, kinesthetic immersion is developed accounting to the unique characteristics of VR context. As for practical implication, the different functions of VR can meet the different needs of 
the students. When students need to improve their sense of distance, the platform can use VR's spatial immersion to help reduce spatial distance. For teacher and students, importing VR technology into the classroom can not only help solving existing problems, but also change the classroom into a highly interactive space to educate. Different teaching scenarios can use different functions. VR technology can not only benefit online platforms, but can also bring some business opportunities for related technical companies. These company can develop VR related tools for proving better usage experiences for both online platforms and students.

\section{REFERENCES}

[1] G.-J. Hwang, C.-L. Lai, and S.-Y. Wang, "Seamless flipped learning: A mobile technology enhanced flipped classroom with effective learning strategies," Journal of Computers in Education, vol. 2, no. 4, pp. 449-473, 2015.

[2] S. M. Ross, G. R. Morrison, and D. L. Lowther, "Educational technology research past and present: balancing rigor and relevance to impact learning," Contemporary Educational Technology, vol. 1, no. 1, pp. $17-35,2010$.

[3] M. Masson, "Benefits of TED talks," Canadian Family Physician, vol. 60, no. 12, pp. 1080-1080, 2014.

[4] D. Christian, "Social software: E-learning beyond learning management systems," European Journal of Open, Distance and e-Learning, vol. 9, no. 2, 2006.

[5] M. Schramm, "Study: iPads improve kindergarten literacy scores," AOL Tech, 2012.

[6] J. Voogt and G. Knezek, "International handbook of information technology in primary and secondary education," Springer Science \& Business Media, US, 2018, pp. 215-230.

[7] L. Cuban, "High-tech schools and low-tech teaching: A commentary," Journal of Computing in Teacher Education, vol. 14, no. 2, pp. 6-7, 1998.

[8] M. Trucano, "More about MOOCc and developing countries," EduTceh:A World Bank Blog on ICT Use in Education, 2013.

[9] J. Y. Shi et al., "Virtual reality and mixed reality for virtual learning environments," Journal of Computers \& Graphics, vol. 30, no. 1, pp. 20-28, 2006.

[10] Velev, Dimiter, Zlateva, and Plamena, "Augmented and virtual reality application in disaster preparedness training for society resilience," International Multidisciplinary Scientific GeoConference: SGEM: Surveying Geology \& mining Ecology Management, vol. 18, no. 4, pp. 195-201, 2018.
[11] C. Baker, "The impact of instructor immediacy and presence for online student affective learning, cognition, and motivation," Journal of Educators Online, vol. 7, no. 1, 2010.

[12] R. Manseur, "Virtual reality in science and engineering education," in Proc. Frontiers in Education 35th Annual Conference, F2E-8, 2005.

[13] S. B. Eom, H. J. Wen, and N. Ashill, "The determinants of students" perceived learning outcomes and satisfaction in university online education: An empirical investigation," Decision Sciences Journal of Innovative Education, vol. 4, no. 2, pp. 215-235, 2006.

[14] R. Williams and M. Dargel, "From servicescape to "cyberscape"," Journal of Marketing Intelligence \& Planning, vol. 22, no. 3, pp. 310-320, 2004.

[15] Z. Merchant et al., "The learner characteristics, features of desktop 3D virtual reality environments, and college chemistry instruction: A structural equation modeling analysis," Journal of Computers \& Education, vol. 59, no. 2, pp. 551-568, 2012.

[16] T. Monahan, G. McArdle, and M. Bertolotto, "Virtual reality for collaborative e-learning," Journal of Computers \& Education, vol. 50, no. 4, pp. 1339-1353, 2008.

[17] Ben-Zion, "A characterization of the price behavior of international dual stocks: an error correction approach," Journal of International Money and Finance, vol. 18, no. 2, pp. 289-304, 1999.

[18] P. R. Dark, M. K. Brady, R. L. Benedicktus, and A. E. Willson, "Feeling close from afar: The role of psychological distance in offsetting distrust in unfamiliar online retailers," Journal of Retailing, vol. 92, no. 3, pp. 287-299, 2016.

[19] B.-A. Yoav, N. Liberman, and Y. Trope, "The Association between psychological distance and construal level: Evidence from an implicit association test," Journal of Experimental Psychology: Generall, vol. 35 , no. 4 , pp. $609,2006$.

Copyright (C) 2020 by the authors. This is an open access article distributed under the Creative Commons Attribution License which permits unrestricted use, distribution, and reproduction in any medium, provided the original work is properly cited (CC BY 4.0).

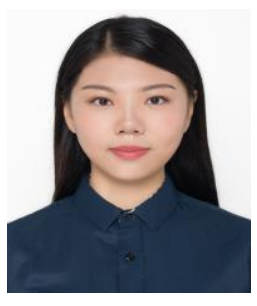

Lyu Hongyu was born in China on July 30, 1995. She gratuded from Hanshan Normal University which located in Guang Dong province of China. It'S undergraduate degree. Her major is ideological and political education.

She has won the first-class scholarship and the third-class scholarship. After graduation, she worked as an operations assistant in a trading company in Guang Dong province of China. 